\title{
Bagasse Cellulose Grafted with an Amino-Terminated Hyperbranched Polymer for the Removal of Cr(VI) from Aqueous Solution
}

\author{
Lu Xia ${ }^{1,2}$, Zhonghang Huang ${ }^{1,2}$, Lei Zhong ${ }^{1,3, *}$, Fengwei Xie ${ }^{4,5, *(\mathbb{D}}$, Chak Yin Tang ${ }^{6}$ and \\ Chi Pong Tsui ${ }^{6}$ \\ 1 School of Chemistry and Chemical Engineering, Guangxi University for Nationalities, \\ Nanning 530006, China; leiwin@163.com (L.X.); zhfp1666@163.com (Z.H.) \\ 2 Guangxi Key Laboratory of Chemistry and Engineering of Forest Products, Guangxi University for Nationalities, \\ Nanning 530006, China \\ 3 Guangxi Key Laboratory Cultivation Base for Polysaccharide Materials and Modifications, \\ Guangxi University for Nationalities, Nanning 530006, China \\ 4 Institute of Advanced Study, University of Warwick, Coventry CV4 7HS, UK \\ 5 International Institute for Nanocomposites Manufacturing (IINM), WMG, University of Warwick, \\ Coventry CV4 7AL, UK \\ 6 Department of Industrial and Systems Engineering, The Hong Kong Polytechnic University, Hung Hom, \\ Kowloon, Hong Kong, China; cy.tang@polyu.edu.hk (C.Y.T.); gary.c.p.tsui@polyu.edu.hk (C.P.T.) \\ * Correspondence: leiwin@gmail.com (L.Z.); D.Xie.2@warwick.ac.uk (F.X.); Tel.: +86-771-326-7019 (L.Z.)
}

Received: 1 August 2018; Accepted: 18 August 2018; Published: 20 August 2018

\begin{abstract}
A novel bio-adsorbent was fabricated via grafting an amino-terminated hyperbranched polymer $\left(\mathrm{HBP}-\mathrm{NH}_{2}\right)$ onto bagasse cellulose. The morphology and microstructure of the $\mathrm{HBP}-\mathrm{NH}_{2}$-grafted bagasse cellulose $(\mathrm{HBP}-\mathrm{g}-\mathrm{BC})$ were characterized and its adsorption capacity for $\mathrm{Cr}(\mathrm{VI})$ ions in aqueous solutions was investigated. The rough surface structure of HBP-g-BC that is beneficial for improving the adsorption capacity was observed by scanning electron microscopy (SEM). The grafting reaction was confirmed by Fourier-transform infrared (FT-IR) spectroscopy. The adsorbent performance was shown to be better with a lower $\mathrm{pH}$ value, a higher adsorbent dosage, or a higher initial $\mathrm{Cr}(\mathrm{VI})$ concentration. Moreover, the kinetics study revealed that the adsorption behavior followed a pseudo-second-order model. The isotherm results showed that the adsorption data could be well-fitted by the Langmuir, Freundlich, or Temkin models. Moreover, HBP- $g$-BC could maintain $74.4 \%$ of the initial removal rate even after five cycles of regeneration. Thus, the high potential of HBP- $g$-BC as a bio-adsorbent for heavy metal removal has been demonstrated.
\end{abstract}

Keywords: bagasse cellulose; hyperbranched polymer; adsorption capacity; $\mathrm{Cr}(\mathrm{VI})$ removal

\section{Introduction}

Chromium is one of the most common heavy metals used in industry and has a broad range of industrial applications, such as electroplating and metal processing. It is well-known that chromium ions $\mathrm{Cr}(\mathrm{VI})$ possess significantly higher toxicity than other forms of chromium. Without proper treatment, wastewater containing $\mathrm{Cr}(\mathrm{VI})$ may cause serious environmental problems [1,2]. Wastewater containing $\mathrm{Cr}(\mathrm{VI})$ is highly toxic to plants and animals even at low concentrations. Contact with $\mathrm{Cr}(\mathrm{VI})$ can cause ulcerations and dermatitis on the skin. Inhalation of $\mathrm{Cr}(\mathrm{VI})$ can result in serious gastrointestinal and neurological problems [3]. It has also been reported that ingestion of $\mathrm{Cr}(\mathrm{VI})$ through contaminated drinking water could potentially cause mouth or stomach cancers [4]. Therefore, the removal of $\mathrm{Cr}(\mathrm{VI})$ from wastewater is essential to protect the environment and maintain human health. 
For the removal of heavy metals from wastewater, different methods, such as precipitation, solvent extraction, ion exchange, membrane filtration, and adsorption [5-7], have been used. The precipitation process removes heavy metals by forming precipitates that can be separated from water. This process is relatively simple and inexpensive, but sometimes causes disposal and separation problems [5]. In the solvent extraction process, organic solvents that are immiscible with water are added into wastewater to dissolve and remove heavy metals. This method is well-established and easy to operate, but it is only effective in removing certain types of metals [8]. The ion exchange process uses specific resins to exchange their cations or anions with heavy metals and remove them from wastewater. The advantages of it include high capacity, selectivity, and fast kinetics, whereas the main disadvantage is that ion exchange is not suitable for a concentrated metal solution and is highly sensitive to $\mathrm{pH}$ values [9]. Membrane filtration shows great potential in wastewater treatment. It can achieve a high removal efficiency and involves no phase change. The membrane filtration techniques, such as ultrafiltration (UF), reverse osmosis (RO), and nanofiltration (NF), have been used for heavy metal removals [10]. UF uses a permeable membrane of a pore size of 5-20 nm to separate heavy metals. It can work at low driving force in a small working space, but needs to overcome the adverse effects caused by membrane fouling [11]. RO utilizes a semipermeable membrane that allows for the passage of solvent and retains the metals. $\mathrm{RO}$ has been widely used in desalination, but its application in heavy metal removal is still limited because of the high energy consumption [5]. NF is a promising technology in membrane filtration. It provides an intermediate process between UF and RO. It is an easy, reliable, and energy-saving process with high removal efficiency. However, NF is relatively new and has some issues, such as the disposal of NF concentrate and membrane fouling, which hinder its further application [12].

The adsorption process uses adsorbents to remove heavy metals. During the adsorption, heavy metals are transferred from wastewater and adhered to the surface of the adsorbent by the physical and/or chemical interactions between them. Among various water treatment processes, adsorption is considered to be one of the most efficient techniques because of its good operational flexibility, high efficiency, and excellent reusability $[13,14]$. In recent years, more and more efforts have devoted to searching for low-cost and highly efficient adsorbents [15-17].

Cellulose is a natural biopolymer that is widely available and environmentally friendly. It has high potential to be developed into bio-adsorbents for wastewater treatment $[18,19]$. As cellulose contains a significant amount of hydroxyl groups, it has high affinity with heavy metal ions, which is beneficial for eliminating heavy metal ions from aqueous solutions [20,21]. Recently, the fabrication of different forms of cellulosic adsorbents and their adsorption behaviors for heavy metal ions have been widely investigated [22]. Hajeeth et al. [23] fabricated an adsorbent by grafting an acrylonitrile monomer onto cellulose extracted from a sisal fiber for the removal of $\mathrm{Cr}(\mathrm{VI})$ from aqueous solutions. The highest removal rate was $86.2 \%$. Zhong et al. [24] utilized an adsorbent derived from wheat straw for eliminating $\mathrm{Cu}(\mathrm{II})$ and $\mathrm{Cr}(\mathrm{VI})$ from wastewater. The maximum adsorption capacity for $\mathrm{Cu}(\mathrm{II})$ and $\mathrm{Cr}(\mathrm{VI})$ was 17.1 and $62.2 \mathrm{mg} / \mathrm{g}$, respectively. More recently, d'Halluin et al. [25] reported the use of chemically modified cellulose filter paper for the adsorption of various heavy metals in water, with a high removal rate of $90-95 \%$.

Sugarcane bagasse is an important by-product of the sugarcane industry. There has been a growing interest in finding new applications for this cheap resource. Although the adsorption capacity of coarse sugarcane is not satisfactory, chemically modified bagasse cellulosic materials have shown great potential to be used as effective adsorbents for heavy metals [26-28]. Yu et al. [29] investigated the adsorption behaviors of pyromellitic-dianhydride-modified bagasse cellulose for $\mathrm{Pb}(\mathrm{II}), \mathrm{Cd}(\mathrm{II})$, $\mathrm{Zn}(\mathrm{II})$, and $\mathrm{Cu}(\mathrm{II})$ and found that the adsorption capacity of modified bagasse was 10 times higher than that of unmodified bagasse. Zhu et al. [30] synthesized bagasse cellulose through epoxidation and amination, which was used for the elimination of $\mathrm{Cu}(\mathrm{II})$. The adsorption capacity was $35.2 \mathrm{mg} / \mathrm{g}$ under optimal conditions. Ramos et al. [31] modified bagasse cellulose with phthalic anhydride and 
evaluated its adsorption performance for $\mathrm{Co}(\mathrm{II}), \mathrm{Cu}(\mathrm{II})$, and $\mathrm{Ni}(\mathrm{II})$. The maximum adsorption capacities obtained were $0.561,0.935$, and $0.932 \mathrm{mmol} / \mathrm{g}$, respectively.

Hyperbranched polymers (HBPs) are a type of macromolecule with highly branched three-dimensional (3D) structures. Compared with their linear and crosslinked analogs, HBPs exhibit properties such as lower viscosity, higher solubility, and less entanglement due to their unique globular and dendritic architectures. They have been widely used in fields such as coating, nanotechnology, additives, and biomaterials [32]. Since HBPs have abundant functional groups and excellent chelation properties with various metal ions, the introduction of HBPs has recently been considered as an effective way to design and fabricate novel adsorbents for heavy metal ions, such as $\mathrm{Cu}$ (II), $\mathrm{Pb}$ (II), $\mathrm{Zn}$ (II), and $\mathrm{Cr}(\mathrm{VI})[33,34]$. Zang et al. [35] reported an adsorbent prepared by modifying cotton fibers with HBPs, which showed removal rates for $\mathrm{Cu}(\mathrm{II})$ and $\mathrm{Pb}(\mathrm{II})$ to be about 73.5 and $71.2 \mathrm{wt} \%$, respectively. Lin et al. [36] investigated the performance of a hyperbranched polyamide-modified corncob adsorbent for $\mathrm{Cr}(\mathrm{VI})$, and the adsorption capacity was shown to be up to $47.8 \mathrm{mg} / \mathrm{g}$. More recently, Li et al. [37] modified chitosan with an amino-terminated hyperbranched polymer, which was applied to remove $\mathrm{Cr}(\mathrm{VI})$. The removal rate was shown to be up to $93.8 \%$. Despite these previous efforts, there is still a variety of natural biopolymers which have strong potential to be used for heavy metal adsorbents and remain to be tested. Biopolymers from agricultural residues, such as sugarcane bagasse, rice straws, corncobs, and wheat straws, have the prominent advantages of being used as biosorbent materials owing to their low cost, good processibility, and high capacity. In particular, sugarcane bagasse is heavily produced and has a high proportion of cellulose [38]. Grafting with an amino-terminated HBP will be an effective way to improve the adsorption performance of sugarcane bagasse cellulose. However, there are limited studies focusing on sugarcane bagasse cellulose modified with HBPs and its adsorption behavior and mechanism as an adsorbent for heavy metal removal.

This work aimed at fabricating a novel bio-adsorbent based on sugarcane bagasse cellulose (BC) grafted with an amino-terminated hyperbranched polymer $\left(\mathrm{HBP}-\mathrm{NH}_{2}\right)$ and evaluating the adsorption capacity of this bio-adsorbent for $\mathrm{Cr}(\mathrm{VI})$ ions in aqueous solutions. The morphology and microstructure of the fabricated $\mathrm{HBP}-\mathrm{NH}_{2}$-grafted bagasse cellulose (HBP-g-BC) were characterized by SEM and FT-IR. The effects of $\mathrm{pH}$, adsorbent dosage, and initial $\mathrm{Cr}(\mathrm{VI})$ concentration on the adsorption behavior of the bio-adsorbent were also examined. Moreover, the adsorption mechanism was explored by a kinetics and an isotherm analysis.

\section{Materials and Methods}

\subsection{Materials and Chemicals}

Coarse sugarcane bagasse was supplied by Nanning Sugar Industry Co., Ltd. (Nanning, China). Anhydrous sodium sulfate (AR), sodium periodate (AR), and ethylene glycol (AR) were purchased from Kelong Chemical Reagent Factory (Chengdu, China). Diethylenetriamine (AR), methyl acrylate (AR), methanol (AR), glacial acetic acid (AR), and anhydrous ethanol (AR) were purchased from Sinopharm Chemical Reagent Co., Ltd. (Shanghai, China). Potassium dichromate (AR) was supplied by Guanghua Chemical Reagent Factory (Shantou, China). Deionized water was made in the lab and used in all the experiments.

\subsection{Preparation of Bagasse-Based Adsorbent}

\subsubsection{Synthesis of Dialdehyde Bagasse Cellulose (DABC)}

Dialdehyde bagasse cellulose (DABC) was prepared according to Huang et al. [39]. Coarse bagasse cellulose was firstly ground and purified by reaction with anhydrous sodium sulfate. Then, the purified $\mathrm{BC}$ was mixed with sodium periodate. Based on our preliminary experiments, the synthesis conditions used were the temperature of $35^{\circ} \mathrm{C}$, the reaction time of $3.5 \mathrm{~h}$, the $\mathrm{pH}$ of 3 , and the mass ratio of sodium periodate to cellulose of 2:1, which could allow abundant aldehyde groups to be generated. Then, $5 \mathrm{~mL}$ 
of ethylene glycol was added into the mixture of cellulose and periodate for another $1 \mathrm{~h}$ of reaction. Afterwards, the mixture was filtered and washed with deionized water and anhydrous ethanol three or four times to obtain the solids. Finally, DABC powder was obtained by vacuum-drying the solid at $40{ }^{\circ} \mathrm{C}$ until reaching a constant weight.

\subsubsection{Synthesis of $\mathrm{HBP}-\mathrm{NH}_{2}$}

$\mathrm{HBP}-\mathrm{NH}_{2}$ was prepared by the polycondensation procedure introduced by Wang et al. [40]. An amount of $52 \mathrm{~mL}$ of diethylenetriamine was added to a three-necked flask and cooled by submerging in an ice cooling bath. Then, under the protection of nitrogen, $43 \mathrm{~mL}$ of methyl acrylate and $100 \mathrm{~mL}$ of methanol were mixed and slowly poured into a flask to react at room temperature. After $3 \mathrm{~h}$ of reaction, $\mathrm{AB}_{2}$ and $\mathrm{AB}_{3}$ monomers were obtained. These two types of monomers were transferred to an eggplant flask attached to a rotary evaporator to react. During the reaction, firstly the methanol was removed by decompression. Then, the temperature was increased to $150{ }^{\circ} \mathrm{C}$ and the reaction was carried on under decompression for another $4 \mathrm{~h}$ to obtain $\mathrm{HBP}^{-\mathrm{NH}_{2}}$.

\subsubsection{Synthesis of $\mathrm{HBP}_{-} \mathrm{NH}_{2}$-Grafted Bagasse Cellulose (HBP-g-BC)}

Ten grams $(10 \mathrm{~g})$ of dried DABC powders and $100 \mathrm{~mL}$ of methanol were added to a three-necked flask. They were mixed by stirring and heating at $45^{\circ} \mathrm{C}$. When the temperature of the solution reached $45^{\circ} \mathrm{C}, 5 \mathrm{~mL}$ of glacial acetic acid was added for another 20-30 min of reaction. Then, $40 \mathrm{~g}$ of an $\mathrm{HBP}-\mathrm{NH}_{2}$ methanol solution (the volume ratio of $\mathrm{HBP}-\mathrm{NH}_{2}$ to methanol was 1:1) was added to react with DABC for $7 \mathrm{~h}$ to obtain HBP- $g$-BC. Afterwards, the obtained cellulose was washed with deionized water and ethanol and was then filtered by suction to form a filter cake. The final product was obtained by vacuum-drying the filter cake under $40^{\circ} \mathrm{C}$ until it reached a constant weight.

\subsection{Fourier-Transform Infrared (FT-IR) Spectroscopy}

The Fourier-transform infrared (FT-IR) spectra of BC, DABC, and HBP- $g$-BC were measured by a Fourier-transform infrared spectrometer (Nicolette Magna 550II, GMI, Ramsey, MN, USA). A small amount of sample was mixed with $\mathrm{KBr}$ powder. Then, the blend was ground and compressed to form the testing disc. The spectral range of $4000-400 \mathrm{~cm}^{-1}$ was used for analysis of each sample.

\subsection{Microscopy}

The surface morphologies of BC and HBP-g-BC were observed by a field emission scanning electron microscope (Zeiss, Supra 55, Oberkochen, Germany) with an accelerating voltage ranging from 0.02 to $30 \mathrm{kV}$ and a resolution of $0.8 \mathrm{~nm}$.

\subsection{Thermogravimetric Analysis}

The thermal stabilities of $\mathrm{BC}$ and $\mathrm{HBP}-\mathrm{g}-\mathrm{BC}$ were measured by a simultaneous thermal analyzer (DSC/DTA-TG, STA 449 F3 Jupiter, Netzsch, Selb, Germany). The samples were heated from 35 to $900{ }^{\circ} \mathrm{C}$ with a heating rate of $10{ }^{\circ} \mathrm{C} / \mathrm{min}$.

\subsection{Adsorption Study}

\subsubsection{Adsorption Procedure}

Solutions were prepared to simulate wastewater produced from a metal processing unit [41]. A certain amount of potassium dichromate was dissolved in deionized water. The $\mathrm{pH}$ value of $\mathrm{Cr}(\mathrm{VI})$ solution was adjusted by addition of $\mathrm{HCl}$ or $\mathrm{NaOH}$.

To conduct a batch mode adsorption test, a certain amount of HBP-g-BC was added to the prepared $\mathrm{Cr}(\mathrm{VI})$ solution at a certain temperature and a $\mathrm{pH}$ value. The adsorption was carried out in a rotary shaker at a speed of $200 \mathrm{rpm} / \mathrm{min}$ for different time periods. 
A series of batch adsorption tests were conducted to investigate the effects of $\mathrm{pH}$, adsorbent dosage and initial $\mathrm{Cr}(\mathrm{VI})$ concentration on the adsorption performance of HBP-g-BC. For each set of conditions, the measurements were carried out in triplicate for different samples to ensure the reproducibility of the data. The mean values were calculated and used for further analysis.

\subsubsection{Determination of Adsorption Capacity}

The metal ion adsorption capacity of HBP- $g$-BC was determined by the adsorption amount $q$ and the removal rate $R$, which can be calculated by the following two equations.

$$
\begin{gathered}
q=\frac{\left(C_{0}-C_{e}\right) V}{M} \\
R=\frac{\left(C_{0}-C_{e}\right)}{C_{0}} \times 100 \%
\end{gathered}
$$

In these equations, $C_{0}$ and $C_{e}$ are the concentrations $(\mathrm{mg} / \mathrm{L})$ of metal ions in the solution before and after the adsorption, respectively, $V$ is the volume (L) of the aqueous solution, and $M$ is the mass (g) of HBP-g-BC consumed during the adsorption.

\subsection{Regeneration Study}

For adsorption, $0.1 \mathrm{~g}$ of $\mathrm{HBP}-\mathrm{g}$-BC was added to $50 \mathrm{~mL}$ of $\mathrm{Cr}(\mathrm{VI})$ solution $(20 \mathrm{mg} / \mathrm{L})$ at $35^{\circ} \mathrm{C}$ and $\mathrm{pH}=3$ in a conical flask. The adsorption process was carried out for $4 \mathrm{~h}$. Afterwards, the adsorbent was treated with $0.1 \mathrm{~mol} / \mathrm{L} \mathrm{HCl}$ for $24 \mathrm{~h}$ and was then filtered. The filtrate was used for desorption analysis. Then, the adsorbent was washed with distilled water to remove the residual acid and to ready it for the next desorption test. The above procedure was repeated for five cycles to evaluate the reusability of the adsorbent.

\section{Results and Discussions}

\subsection{FT-IR Analysis of Unmodified and Modified Bagasse Celluloses}

The FT-IR spectra of BC, DABC, and HBP-g-BC are shown in Figure 1. It can be seen that the shapes of these three curves are similar. The broad band observed around $3400 \mathrm{~cm}^{-1}$ is considered to be due to the hydroxyl (-OH) stretching. The characteristics peak around $2900 \mathrm{~cm}^{-1}$ could be ascribed to the $\mathrm{C}-\mathrm{H}$ vibration. Compared with that of $\mathrm{BC}$, the spectrum of $\mathrm{DABC}$ shows a characteristic adsorption peak of carbonyl group at $1726 \mathrm{~cm}^{-1}$, suggesting that aldehyde groups were introduced to $B C$ to form DABC [39]. In the spectrum of HBP-g-BC, this peak of aldehyde group disappears, the peak of $\mathrm{C}-\mathrm{H}$ vibration at 2921 moves to $2893 \mathrm{~cm}^{-1}$, and there is a new characteristic peak at $1544 \mathrm{~cm}^{-1}$, which could be assigned to the vibration of amine groups. This indicates that through the reaction between the aldehyde groups of DABC and the amino groups of $\mathrm{HBP}-\mathrm{NH}_{2}, \mathrm{HBP}-\mathrm{NH}_{2}$ was successfully grafted onto BC to form HBP-g-BC [37]. 


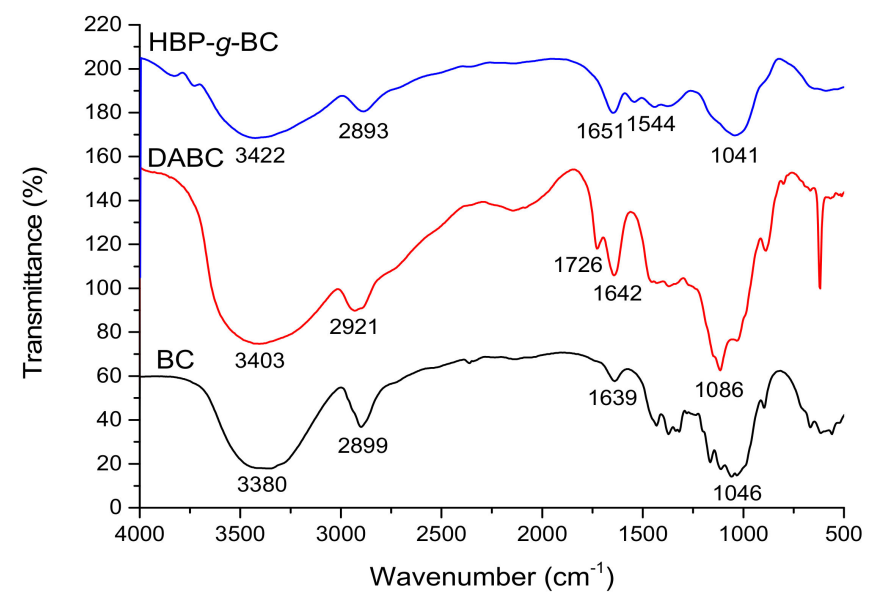

Figure 1. FT-IR spectra of Bagasse Cellulose (BC), Dialdehyde Bagasse Cellulose (DABC), and $\mathrm{HBP}-\mathrm{NH}_{2}$-Grafted Bagasse Cellulose (HBP-g-BC).

\subsection{SEM of Unmodified and Modified Bagasse Celluloses}

The SEM images of BC, DABC, and HBP- $g$-BC are presented in Figure 2. At the same magnification, while the surface of $B C$ (without modification) was smooth and compact, the modification made the surface become loose and rough. Furthermore, the surface of HBP-g-BC had some small peaks with irregular shapes. This surface feature presenting a higher specific surface area could lead to an increased number of active adsorption sites and thus an improved adsorption capacity of HBP- $g$-BC.

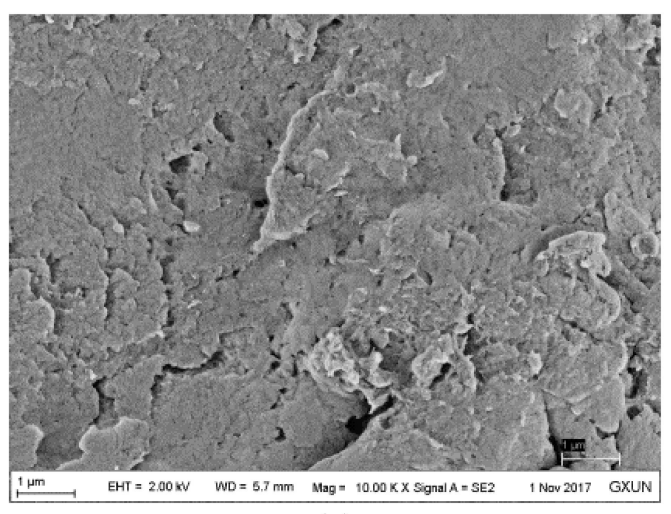

(a)

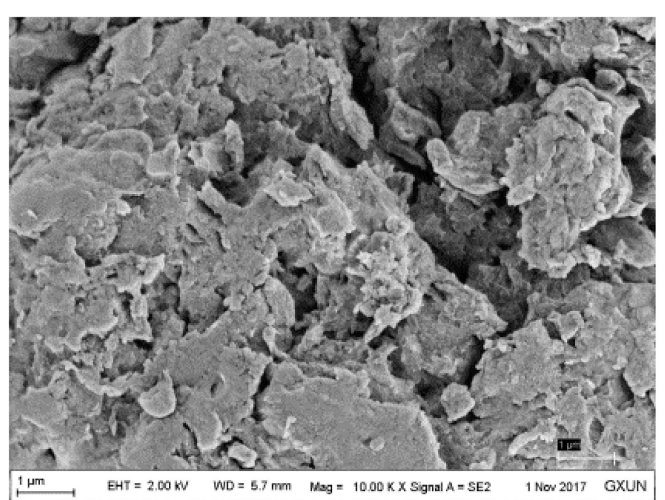

(b)

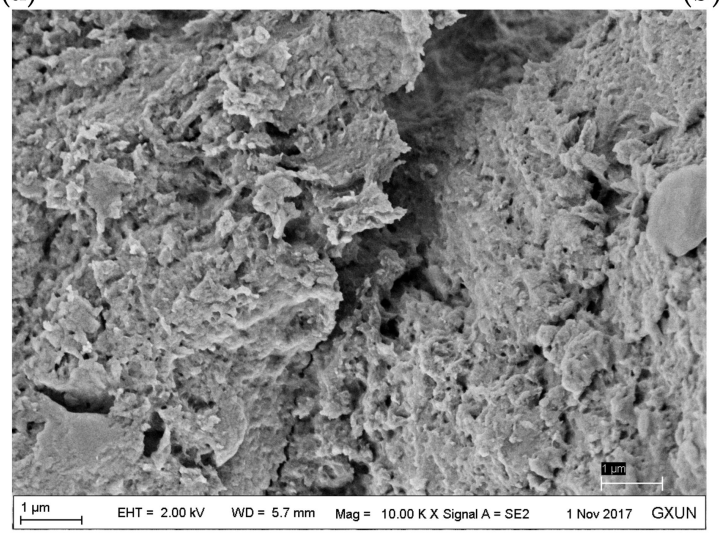

(c)

Figure 2. SEM images of BC (a), DABC (b), and HBP- $g$-BC (c). 


\section{3. $T G A$ of $B C$ and $H B P-g-B C$}

Figure 3 shows the TGA results of $\mathrm{BC}$ and HBP-g-BC. Three stages of weight loss can be observed for both BC and HBP-g-BC. At the initial stage $\left(35-242{ }^{\circ} \mathrm{C}\right.$ for BC and $35-172{ }^{\circ} \mathrm{C}$ for HBP-g-BC), the weight loss of $\mathrm{BC}$ and $\mathrm{HBP}-\mathrm{g}-\mathrm{BC}$ was $2.7 \%$ and $11.2 \%$, respectively. This first-stage weight loss could be mostly ascribed to the moisture evaporation. The major weight loss occurred at the second stage $\left(242-400{ }^{\circ} \mathrm{C}\right.$ for $\mathrm{BC}$ and $172-400{ }^{\circ} \mathrm{C}$ for HBP-g-BC), during which the weight losses for BC and HBP- $g$-BC reached $73.6 \%$ and $56.9 \%$, respectively. This second-stage weight loss could be attributed to the degradation and decomposition of $\mathrm{BC}$ and HBP- $g-\mathrm{BC}$. The onset temperature for the significant weight loss of HBP-g-BC was lower than that for BC. Regarding this, the introduction of $\mathrm{HBP}-\mathrm{NH}_{2}$ groups might make the polymer easier to decompose. The results are consistent with those in previous studies, where the decomposition temperature of cellulose usually decreased by grafting with hyperbranched polymers [37].

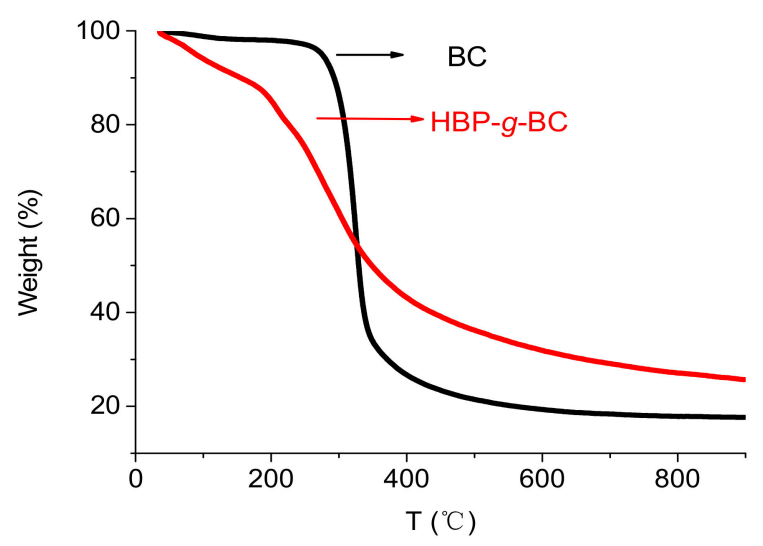

Figure 3. TGA curves of BC and HBP-g-BC.

\section{Evaluation of Adsorption Capacity of HBP-g-BC}

\subsection{Effect of Solution $\mathrm{pH}$}

The $\mathrm{pH}$ of an aqueous solution significantly affects the ionic forms of heavy metals and the surface charge of an adsorbent in the solution. Therefore, $\mathrm{pH}$ strongly influences the adsorption capacity of the adsorbent for $\mathrm{Cr}(\mathrm{VI})$ ions. $\mathrm{Cr}(\mathrm{VI})$ is more reactive at low $\mathrm{pH}$ values because its reduction potential decreases with increasing $\mathrm{pH}$. In our preliminary experiments, the change in adsorption capacity is small when the $\mathrm{pH}$ value is higher than 6 . To investigate the effect of $\mathrm{pH}$, the adsorption tests were carried out at $\mathrm{pH}$ values from 2 to 6 [37]. The relationship between the adsorption capacity for $\mathrm{Cr}$ (II) and the $\mathrm{pH}$ is shown in Figure 4. It can be seen that with the increased $\mathrm{pH}$, both the adsorption capacity and the removal rate decreased. As previously reported about a chitosan-based bio-adsorbent, a higher $\mathrm{Cr}(\mathrm{VI})$ adsorption capacity usually occurs at a $\mathrm{pH}$ value lower than 4 [37]. The greater adsorption capacity for $\mathrm{Cr}(\mathrm{VI})$ at a low $\mathrm{pH}$ value might be explained by the surface protonation of HBP-g-BC. The protonation of amino groups was more active under acidic conditions. In this case, the surface of $\mathrm{HBP}-\mathrm{g}$-BC was strongly positively charged. Moreover, since $\mathrm{Cr}(\mathrm{VI})$ mainly exists in the solution in the forms of $\mathrm{HCrO}_{4}{ }^{-}$and $\mathrm{CrO}_{4}{ }^{2-}$ at low $\mathrm{pH}$ values, the strong electrostatic attraction makes it easy for the adsorbent to capture negatively charged $\mathrm{Cr}(\mathrm{VI})$ ions, leading to a higher adsorption capacity. On the contrary, high $\mathrm{pH}$ values usually reduce the degree of protonation of amino groups, which might negatively influence the adsorption performance of HBP- $g-B C$. 


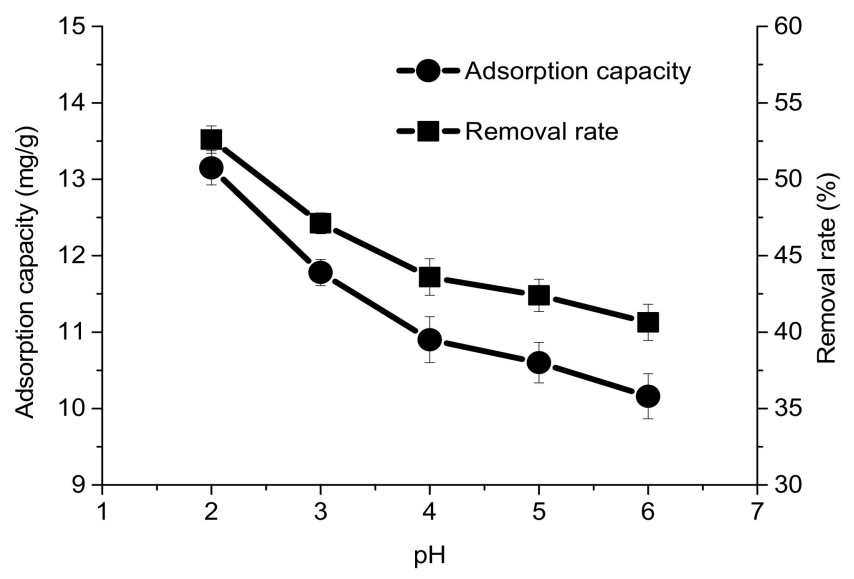

Figure 4. Effect of solution $\mathrm{pH}$ on the adsorption capacity and removal rate for $\mathrm{Cr}(\mathrm{VI})$.

\subsection{Effect of Adsorbent Dosage}

Adsorbent dosage is an important parameter that should be evaluated and controlled in the wastewater treatment. The results (Figure 5) show that the adsorption capacity for $\mathrm{Cr}(\mathrm{VI})$ decreased with increasing the dosage of the adsorbent from 1 to $10 \mathrm{~g} / \mathrm{L}$, which might be due to the unsaturation of active sites on the surface of each adsorbent [30,37]. However, the removal rate of $\mathrm{Cr}(\mathrm{VI})$ increased with increasing the dosage of the adsorbent. This is as expected since, with a higher amount of the adsorbent, the total surface area is increased and thus there are more active sites available for the adsorption [23].
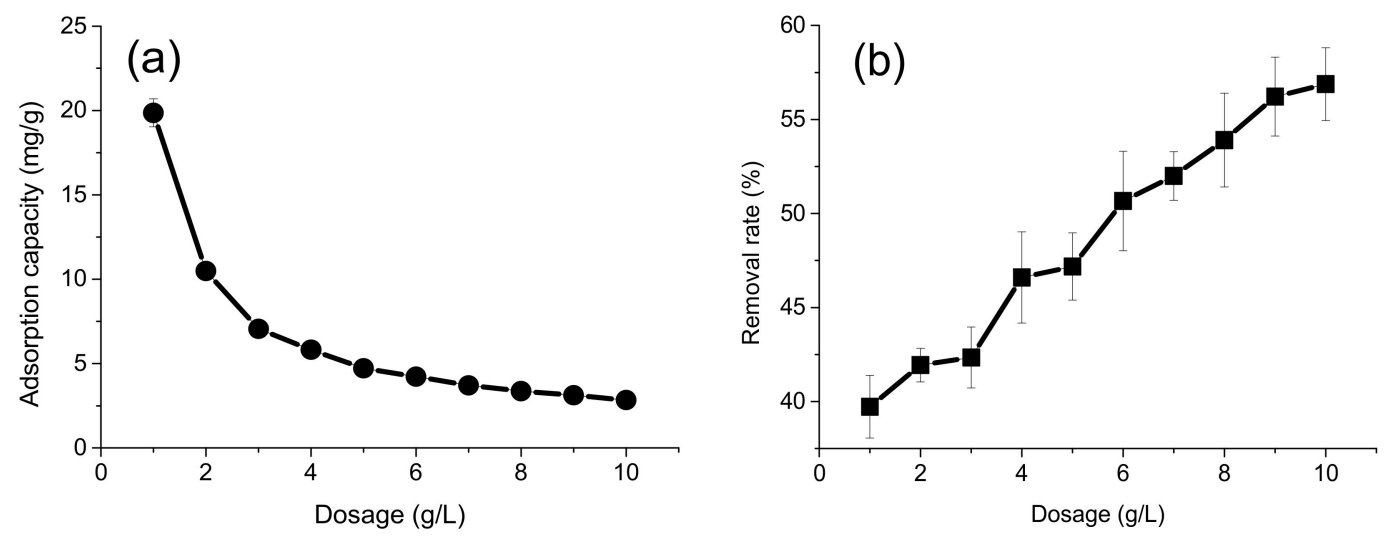

Figure 5. Effect of adsorbent dosage on the adsorption capacity (a) and removal rate (b) for $\mathrm{Cr}(\mathrm{VI})$.

\subsection{Effect of Initial Cr(VI) Concentration}

Figure 6 shows the adsorption capacity and removal rate as a function of the initial concentration of $\mathrm{Cr}(\mathrm{VI})$ between 20 and $80 \mathrm{mg} / \mathrm{L}$. It was found that the adsorption capacity increased with an increase in the initial $\mathrm{Cr}(\mathrm{VI})$ concentration. When the initial concentration was $80 \mathrm{mg} / \mathrm{L}$, the adsorption capacity reached $18.80 \mathrm{mg} / \mathrm{g}$, 3.6 times higher than the capacity when the initial concentration was $20 \mathrm{mg} / \mathrm{L}$, which was $5.18 \mathrm{mg} / \mathrm{g}$. Regarding this, when the initial concentration is higher, there is a larger concentration gradient and the driving force for transferring the metal ions is also stronger. This provides more opportunities for $\mathrm{Cr}(\mathrm{VI})$ ions to be in contact with the adsorbent. Accordingly, more ions will be attached to the active sites on the adsorbent surface, leading to a higher adsorption capacity. The removal rates for different initial $\mathrm{Cr}(\mathrm{VI})$ concentrations were $51.75 \%, 48.40 \%, 46.00 \%, 47.98 \%, 46.05 \%, 46.39 \%$, and $46.99 \%$, respectively. This suggests that HBP- $g$-BC is an excellent adsorbent that can maintain a stable removal rate by increasing its adsorption capacity with increasing initial concentration. 

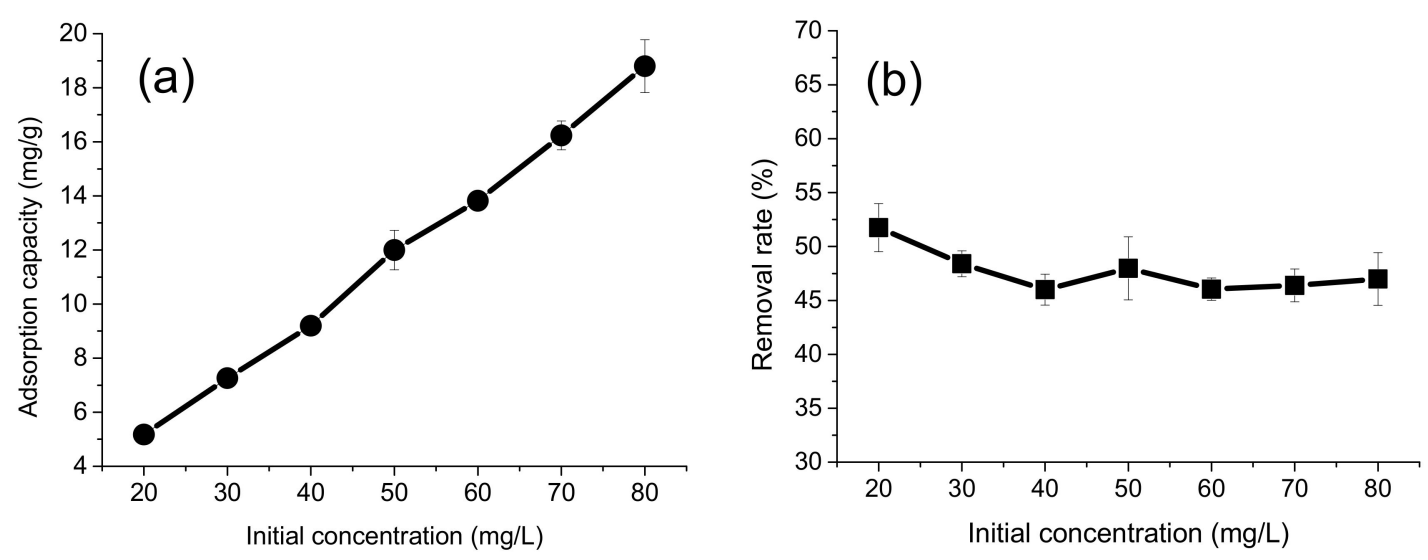

Figure 6. Effect of initial $\mathrm{Cr}(\mathrm{VI})$ concentration on the adsorption capacity (a) and removal rate (b) for $\mathrm{Cr}(\mathrm{VI})$.

\subsection{Adsorption Kinetics}

The adsorption kinetics measurements were conducted at 25,35 , and $45{ }^{\circ} \mathrm{C}$. To investigate the kinetics of the adsorption process, the pseudo-first-order model (Equation (3)) and the pseudo-second-order model (Equation (4)) were used to evaluate the experimental data [42]. The equations of these models are given as follows:

$$
\begin{gathered}
\ln \left(q_{e}-q_{t}\right)=\ln q_{e}-k_{1} t \\
\frac{t}{q_{t}}=\frac{1}{k_{2} q_{e}^{2}}+\frac{t}{q_{e}}
\end{gathered}
$$

In these equations, $q_{e}$ and $q_{t}\left(\mathrm{mg} \cdot \mathrm{g}^{-1}\right)$ are the amount of the $\mathrm{Cr}(\mathrm{VI})$ ions adsorbed at equilibrium and time $t(\mathrm{~min})$, respectively; $k_{1}\left(\mathrm{~min}^{-1}\right)$ is the pseudo-first-order rate constant of the adsorption; and $k_{2}\left(\mathrm{mg} \cdot \mathrm{min}^{-1}\right)$ is the pseudo-second-order rate constant of the adsorption.

As shown in Figure 7a, the pseudo-first-order model fails to describe the kinetics of the adsorption process for $\mathrm{Cr}(\mathrm{VI})$. The correlation coefficients for 25,35 , and $45^{\circ} \mathrm{C}$ were $0.9062,0.9216$, and 0.7793 , respectively. A previous study also showed that for chemically modified cellulose used for $\mathrm{Ag}(\mathrm{I})$, $\mathrm{Pb}(\mathrm{II}), \mathrm{Cd}(\mathrm{II}), \mathrm{Ni}(\mathrm{II}), \mathrm{Zn}(\mathrm{II}), \mathrm{Sn}(\mathrm{II})$, and $\mathrm{Cu}(\mathrm{II})$ adsorptions, the pseudo-first-order model was not suitable [25]. However, as shown in Figure $7 \mathrm{~b}$, the adsorption process can be accurately fitted with the pseudo-second-order model, with the correlation coefficients of $0.9999,0.9941$, and 0.9998 , respectively, for 25,35 , and $45^{\circ} \mathrm{C}$. This suggests that the $\mathrm{Cr}(\mathrm{VI})$ adsorption process might mainly be a chemical adsorption process, which involves valence forces generated by sharing or exchanging electrons between metal ions and the bio-adsorbent [43].

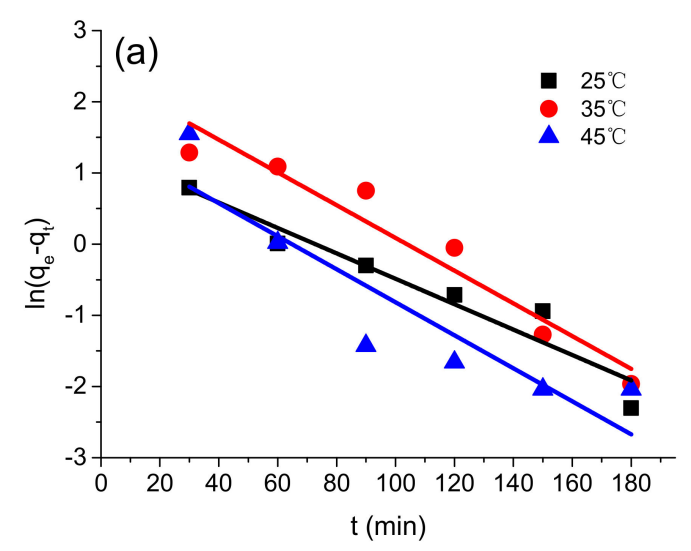

Figure 7. Cont. 


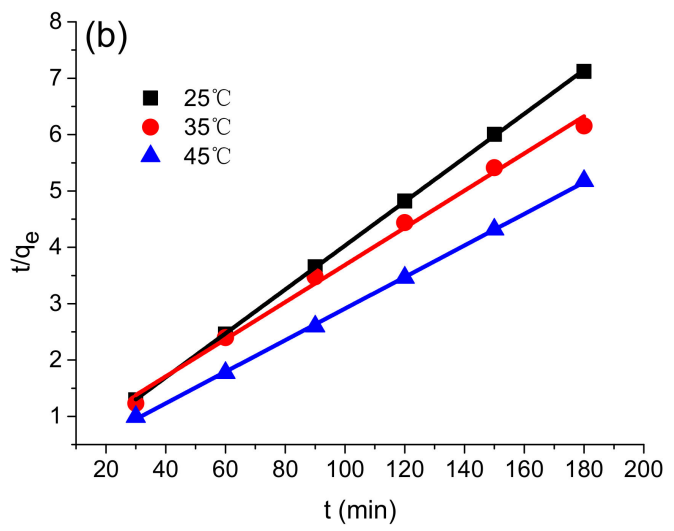

Figure 7. Fitting with the pseudo-first-order model (a) and the pseudo-second-order model (b).

\subsection{Adsorption Isotherms}

The adsorption isotherm model provides a relationship between the amount of adsorbed metal ions and that of the non-adsorbed metal ions in a solution when the equilibrium was reached. It is critical for predicting the adsorption behavior and comparing the adsorbent performance under different conditions [44]. To thoroughly investigate the adsorption isotherm of the HBP-g-BC adsorbent, three widely used isotherm models, namely Langmuir (Equation (5)), Freundlich (Equation (6)), and Temkin (Equation (7)), were used to examine the experimental data [44]:

$$
\begin{gathered}
\frac{1}{q_{e}}=\frac{1}{q_{\max }}+\left(\frac{1}{q_{\max } K_{L}}\right) \frac{1}{C_{e}} \\
\ln q_{e}=\ln K_{F}+\frac{1}{n} \ln C_{e} \\
q_{e}=\left(\frac{R T}{b_{T}}\right) \ln \left(A_{T}\right)+\left(\frac{R T}{b_{T}}\right) \ln \left(C_{e}\right)
\end{gathered}
$$

In these equations, $q_{e}(\mathrm{mg} / \mathrm{g})$ is the amount of metal ions adsorbed at the equilibrium; $C_{e}(\mathrm{mg} / \mathrm{L})$ is the concentration of metal ions in the solution at the equilibrium; $K_{L}$ is the Langmuir constant $(\mathrm{L} / \mathrm{mg}) ; K_{F}$ and $1 / n$ are the Freundlich constants related to the capacity and intensity of the adsorption, respectively; $A_{T}(\mathrm{~L} / \mathrm{g})$ is the Temkin equilibrium constant; $b_{T}$ is the Temkin constant associated with the adsorption heat; $R(8.314 \mathrm{~J} / \mathrm{mol})$ is the gas constant; and $T(\mathrm{~K})$ is the absolute temperature.

The isotherm model parameters for $\mathrm{Cr}(\mathrm{VI})$ ions under three different temperatures are summarized in Table 1 and the regression curves for these three models are plotted in Figure 8. It can be seen that all the three models can properly fit the adsorption process, with high correlation coefficients achieved. The well-fitting of the Freundlich model indicates that the physical adsorption existed during the adsorption process. This might be due to the rough and irregular surface structure of HBP-g-BC, which could easily lead to multilayer physical adsorption on its surface [24]. The Langmuir model also gave a good fit to the measurements. This means that monolayer chemical adsorption of $\mathrm{Cr}(\mathrm{VI})$ ions occurs on the outer surfaces of the adsorbent, which was energetically homogeneous [30]. The Temkin model could accurately describe the adsorption process as well, meaning that there were strong interactions between the adsorbed metals and the adsorbent during the adsorption [25]. 

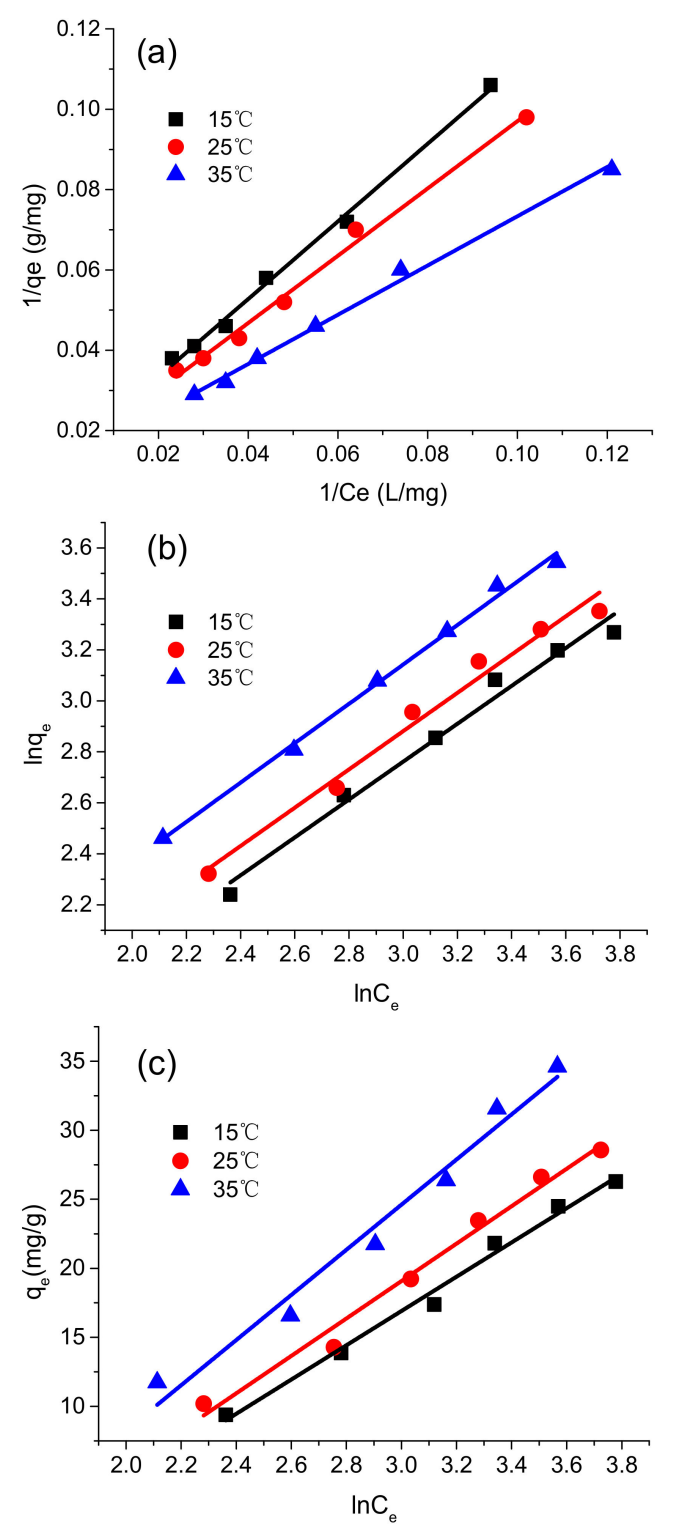

Figure 8. Fitting with isotherm models at different temperatures: Langmuir model (a); Freundlich model (b); and Temkin model (c).

Table 1. Isotherm model parameters of the Langmuir, Freundlich, and Temkin models for HBP-g-BC.

\begin{tabular}{ccccc}
\hline Isotherm Model & Parameters & $\mathbf{1 5}{ }^{\circ} \mathbf{C}$ & $\mathbf{2 5}{ }^{\circ} \mathbf{C}$ & $\mathbf{3 5}^{\circ} \mathbf{C}$ \\
\hline & $q_{\max }(\mathbf{m g} / \mathrm{g})$ & 71.43 & 75.36 & 82.99 \\
Langmuir & $K_{\mathrm{L}}(\mathrm{L} / \mathrm{mg})$ & 0.014 & 0.016 & 0.020 \\
& $R_{\mathrm{L}}$ & 0.505 & 0.472 & 0.417 \\
& $\mathrm{R}^{2}$ & 0.9949 & 0.9916 & 0.9941 \\
\hline \multirow{3}{*}{ Freundlich } & $K_{\mathrm{F}}$ & 1.703 & 1.876 & 2.286 \\
& $n$ & 1.34 & 1.33 & 1.30 \\
& $\mathrm{R}^{2}$ & 0.9784 & 0.9778 & 0.9946 \\
\hline \multirow{3}{*}{ Temkin } & $\mathrm{RT} / b_{\mathrm{T}}$ & 12.413 & 13.556 & 16.348 \\
& $A_{\mathrm{T}}$ & 0.194 & 0.203 & 0.224 \\
& $\mathrm{R}^{2}$ & 0.9876 & 0.9811 & 0.9694 \\
\hline
\end{tabular}


The constant $R_{\mathrm{L}}$ expressed as $R_{\mathrm{L}}=1 /\left(1+K_{\mathrm{L}} C_{0}\right)$ was calculated using the Langmuir model. $R_{\mathrm{L}}$ can be used to effectively evaluate whether the adsorption isotherm process is favorable $\left(0<R_{\mathrm{L}}<1\right)$ or unfavorable $\left(R_{\mathrm{L}}>1\right)$. The $R_{\mathrm{L}}$ values for 15,25 , and $35^{\circ} \mathrm{C}$ were $0.505,0.472$, and 0.417 , respectively, indicating that the adsorption process was favorable. This result corresponds to the $n$ values (1.34, 1.33, and 1.30) calculated by the Freundlich model, since $n$ values in the range of 1 to 10 also suggest a favorable adsorption process. Furthermore, with the increased temperature, both $q_{\max }$ and $K_{\mathrm{L}}$ in the Langmuir model were increased. This suggests that the adsorption of $\mathrm{Cr}(\mathrm{VI})$ by $\mathrm{HBP}-\mathrm{g}-\mathrm{BC}$ was an endothermic process, which means a higher temperature can effectively accelerate the adsorption process.

These results are in agreement with previous research [37]. The possible adsorption process of $\mathrm{Cr}(\mathrm{VI})$ by HBP- $\mathrm{g}-\mathrm{BC}$ might occur in three consecutive stages. Firstly, anionic $\mathrm{Cr}(\mathrm{VI})$ ions bind with the positively charged amino groups of $\mathrm{HBP}-\mathrm{g}-\mathrm{BC}$. Secondly, $\mathrm{Cr}(\mathrm{VI})$ reduces to $\mathrm{Cr}(\mathrm{III})$ by adjacent electron-donor groups. Finally, $\mathrm{Cr}$ (III) reacts with the functional groups on $\mathrm{HBP}-g-\mathrm{BC}$ to form a $\mathrm{Cr}(\mathrm{III})$ complex. It is worth noting that the maximum adsorption capacity of $\mathrm{HBP}-\mathrm{g}-\mathrm{BC}$ for $\mathrm{Cr}(\mathrm{VI})$ at $25^{\circ} \mathrm{C}$ was $75.36 \mathrm{mg} / \mathrm{g}$. In our preliminary studies, the maximum adsorption capacity of DABC was $11.27 \mathrm{mg} / \mathrm{g}$ under the same conditions. It is evident that the grafting of $\mathrm{HBP}-\mathrm{NH}_{2}$ significantly improved the adsorption capacity of BC.

\subsection{Desorption and Regeneration}

The removal rates for $\mathrm{Cr}(\mathrm{VI})$ of regenerated $\mathrm{HBP}-\mathrm{g}$-BC after up to five consecutive adsorption-desorption cycles are presented in Figure 9. It is found that the initial removal rate was $71.25 \%$. After the first recovery cycle, the removal rate decreased to $59.55 \%$. The reason might be that some of the functional groups were destroyed by $\mathrm{HCl}$ during the first recovery process. After the second cycle, the removal rate became stable. After five cycles, the removal rate was $53 \%$, which was $74.4 \%$ of the initial removal rate $(71.25 \%)$. This suggests that HBP- $g$-BC had good reusability and thus has great potential to be used as an economical adsorbent.

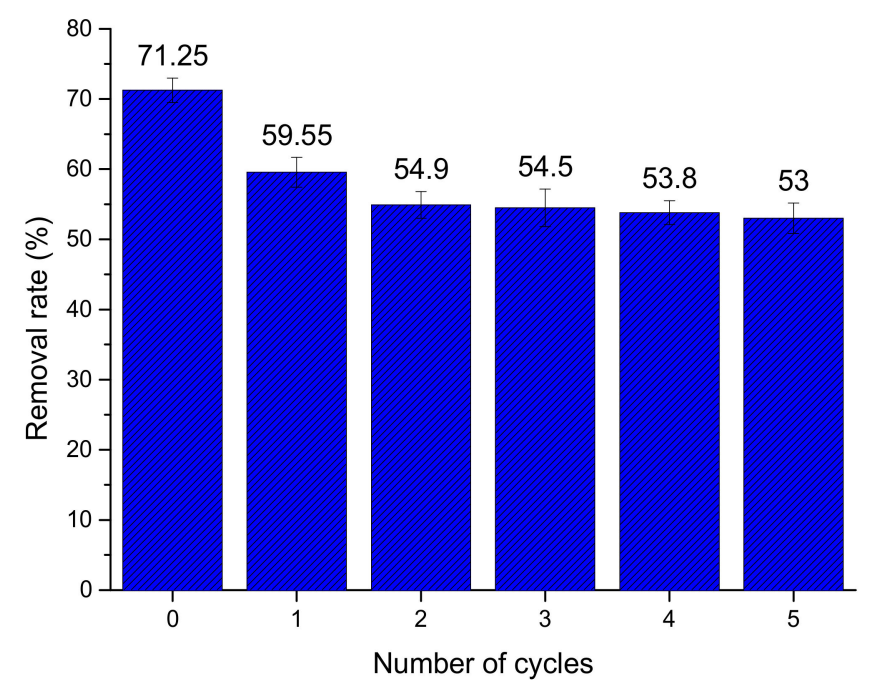

Figure 9. Removal rates of HBP-g-BC after different cycles of regeneration.

\section{Conclusions}

Here, we have demonstrated that the HBP-g-BC bio-adsorbent is capable of removing $\mathrm{Cr}(\mathrm{VI})$ ions from aqueous solutions, and its maximum adsorption capacity for $\mathrm{Cr}(\mathrm{VI})$ was much higher than that of DABC. The introduction of $\mathrm{HBP}-\mathrm{NH}_{2}$ groups onto $\mathrm{BC}$ could lead to a rough and irregular surface, which is instrumental to $\mathrm{Cr}(\mathrm{VI})$ adsorption. We also found that the adsorption performance was highly dependent on the $\mathrm{pH}$, adsorbent dosage, and initial concentration of $\mathrm{Cr}(\mathrm{VI})$. A high adsorption capacity 
could be achieved at a low $\mathrm{pH}$ value due to the surface protonation of HBP- $g$-BC. The removal rate was increased with a higher adsorbent dosage as a higher amount of the adsorbent could provide more active adsorption sites. With the increased initial $\mathrm{Cr}(\mathrm{VI})$ concentration, the adsorption capacity was also increased. Regarding this, the stronger driving force at larger concentration gradients could facilitate the contact between $\mathrm{Cr}(\mathrm{VI})$ ions and the adsorbent. We found that the adsorption kinetics data can be accurately described by the pseudo-second-order model rather than by the pseudo-first-order model. The adsorption isotherm data are in good agreement with the Freundlich, Langmuir, and Temkin models, which means that the adsorption of $\mathrm{Cr}(\mathrm{VI})$ is an endothermic and favorable process. Moreover, $\mathrm{HBP}-\mathrm{g}$-BC could maintain $74.4 \%$ of the initial removal rate even after five cycles of regeneration. Thus, our work has shown the high potential of HBP-g-BC as a bio-adsorbent for heavy metal removal and wastewater treatment.

Author Contributions: Conceptualization, L.X., L.Z. and F.X.; Methodology, L.X., L.Z. and Z.H.; Measurement, L.X. and Z.H.; Data analysis, L.X., Z.H., L.Z. and F.X.; Writing (Original Draft Preparation), L.X., Z.H. and L.Z.; Writing (Review \& Editing), L.Z., F.X., C.Y.T. and C.P.T.

Funding: This research was financially supported by the National Natural Science Foundation of China (NSFC) (No. 41461092), Specific Research Project of Guangxi for Research Bases and Talents (No. 2017AD19029) and the R\&D Fund for the Postgraduate Students of Guangxi University for Nationalities (No. GXUN-CHXZS2016117).

Acknowledgments: L.Z. would like to thank the Xiangsihu Young Scholars Innovative Research Team of Guangxi University for Nationalities for the support. F.X. acknowledges the Institute of Advanced Study, University of Warwick, and the European Commission's Marie Skłodowska-Curie Actions for the Warwick Interdisciplinary Research Leadership Programme (WIRL-COFUND) at the University of Warwick.

Conflicts of Interest: The authors declare no conflict of interest.

\section{References}

1. Xu, S.C.; Pan, S.S.; Xu, Y.; Luo, Y.Y.; Zhang, Y.X.; Li, G.H. Efficient removal of Cr(VI) from wastewater under sunlight by $\mathrm{Fe}(\mathrm{II})$-doped $\mathrm{TiO}_{2}$ spherical shell. J. Hazard. Mater. 2015, 283, 7-13. [CrossRef] [PubMed]

2. Zhao, R.; Li, X.; Sun, B.; Li, Y.; Li, Y.; Yang, R.; Wang, C. Branched polyethylenimine grafted electrospun polyacrylonitrile fiber membrane: A novel and effective adsorbent for $\mathrm{Cr}(\mathrm{VI})$ remediation in wastewater. J. Mater. Chem. A 2017, 5, 1133-1144. [CrossRef]

3. $\mathrm{Hu}, \mathrm{J}$; Chen, G. Fast removal and recovery of $\mathrm{Cr}(\mathrm{VI})$ using surface-modified jacobsite $\left(\mathrm{MnFe}_{2} \mathrm{O}_{4}\right)$ nanoparticles. Langmuir 2005, 21, 11173-11179. [CrossRef] [PubMed]

4. Beaumont, J.J.; Sedman, R.M.; Reynolds, S.D.; Sherman, C.D.; Li, L.-H.; Howd, R.A.; Sandy, M.S.; Zeise, L.; Alexeeff, G.V. Cancer mortality in a Chinese population exposed to hexavalent chromium in drinking water. Epidemiology 2008, 19, 12-23. [CrossRef] [PubMed]

5. Fu, F.; Wang, Q. Removal of heavy metal ions from wastewaters: A review. J. Environ. Manag. 2011, 92, 407-418. [CrossRef] [PubMed]

6. Zhao, M.; Xu, Y.; Zhang, C.; Rong, H.; Zeng, G. New trends in removing heavy metals from wastewater. Appl. Microbiol. Biotechnol. 2016, 100, 6509-6518. [CrossRef] [PubMed]

7. Azimi, A.; Azari, A.; Rezakazemi, M.; Ansarpour, M. Removal of heavy metals from industrial wastewaters: A review. ChemBioEng. Rev. 2017, 4, 37-59. [CrossRef]

8. Gupta, V.K.; Ali, I.; Saleh, T.A.; Nayak, A.; Agarwal, S. Chemical treatment technologies for waste-water recycling-An overview. RSC Adv. 2012, 2, 6380-6388. [CrossRef]

9. Zewail, T.M.; Yousef, N.S. Kinetic study of heavy metal ions removal by ion exchange in batch conical air spouted bed. Alexandria Eng. J. 2015, 54, 83-90. [CrossRef]

10. Barakat, M.A. New trends in removing heavy metals from industrial wastewater. Arab. J. Chem. 2011, 4, 361-377. [CrossRef]

11. Zhang, W.; Grimi, N.; Jaffrin, M.Y.; Ding, L.; Tang, B.; Zhang, Z. Optimization of RDM-UF for alfalfa wastewater treatment using RSM. Environ. Sci. Pollut. Res. 2018, 25, 1439-1447. [CrossRef] [PubMed]

12. Shon, H.K.; Phuntsho, S.; Chaudhary, D.S.; Vigneswaran, S.; Cho, J. Nanofiltration for water and wastewater treatment-A mini review. Drink. Water Eng. Sci. 2013, 6, 47-53. [CrossRef]

13. Bailey, S.E.; Olin, T.J.; Bricka, R.M.; Adrian, D.D. A review of potentially low-cost sorbents for heavy metals. Water Res. 1999, 33, 2469-2479. [CrossRef] 
14. Babel, S. Low-cost adsorbents for heavy metals uptake from contaminated water: A review. J. Hazard. Mater. 2003, 97, 219-243. [CrossRef]

15. Lim, A.P.; Aris, A.Z. A review on economically adsorbents on heavy metals removal in water and wastewater. Rev. Environ. Sci. Bio/Technol. 2014, 13, 163-181. [CrossRef]

16. Inyang, M.I.; Gao, B.; Yao, Y.; Xue, Y.; Zimmerman, A.; Mosa, A.; Pratap, P.; Yong, S.O.; Cao, X. A review of biochar as a low-cost adsorbent for aqueous heavy metal removal. Crit. Rev. Environ. Sci. Technol. 2016, 46, 406-433. [CrossRef]

17. Srivastava, S.; Agrawal, S.B.; Mondal, M.K. A review on progress of heavy metal removal using adsorbents of microbial and plant origin. Environ. Sci. Pollut. Res. 2015, 22, 15386-15415. [CrossRef] [PubMed]

18. Lesmana, S.O.; Febriana, N.; Soetaredjo, F.E.; Sunarso, J.; Ismadji, S. Studies on potential applications of biomass for the separation of heavy metals from water and wastewater. Biochem. Eng. J. 2009, 44, 19-41. [CrossRef]

19. Suhas; Gupta, V.K.; Carrott, P.J.M.; Singh, R.; Chaudhary, M.; Kushwaha, S. Cellulose: A review as natural, modified and activated carbon adsorbent. Bioresour. Technol. 2016, 216, 1066-1076. [CrossRef] [PubMed]

20. O'Connell, D.W.; Birkinshaw, C.; O'Dwyer, T.F. Heavy metal adsorbents prepared from the modification of cellulose: A review. Bioresour. Technol. 2008, 99, 6709-6724. [CrossRef] [PubMed]

21. Yu, X.; Tong, S.; Ge, M.; Wu, L.; Zuo, J.; Cao, C.; Song, W. Adsorption of heavy metal ions from aqueous solution by carboxylated cellulose nanocrystals. J. Environ. Sci. 2013, 25, 933-943. [CrossRef]

22. Hokkanen, S.; Bhatnagar, A.; Sillanpää, M. A review on modification methods to cellulose-based adsorbents to improve adsorption capacity. Water Res. 2016, 91, 156-173. [CrossRef] [PubMed]

23. Hajeeth, T.; Sudha, P.N.; Vijayalakshmi, K.; Gomathi, T. Sorption studies on Cr (VI) removal from aqueous solution using cellulose grafted with acrylonitrile monomer. Int. J. Biol. Macromol. 2014, 66, 295-301. [CrossRef] [PubMed]

24. Zhong, Q.-Q.; Yue, Q.-Y.; Li, Q.; Gao, B.-Y.; Xu, X. Removal of Cu(II) and Cr(VI) from wastewater by an amphoteric sorbent based on cellulose-rich biomass. Carbohydr. Polym. 2014, 111, 788-796. [CrossRef] [PubMed]

25. D’Halluin, M.; Rull-Barrull, J.; Bretel, G.; Labrugère, C.; Le Grognec, E.; Felpin, F.-X. Chemically modified cellulose filter paper for heavy metal remediation in water. ACS Sustain. Chem. Eng. 2017, 5, 1965-1973. [CrossRef]

26. Karnitz, O.; Gurgel, L.V.A.; de Melo, J.C.P.; Botaro, V.R.; Melo, T.M.S.; de Freitas Gil, R.P.; Laurent, F.G. Adsorption of heavy metal ion from aqueous single metal solution by chemically modified sugarcane bagasse. Bioresour. Technol. 2007, 98, 1291-1297. [CrossRef] [PubMed]

27. Homagai, P.L.; Ghimire, K.N.; Inoue, K. Adsorption behavior of heavy metals onto chemically modified sugarcane bagasse. Bioresour. Technol. 2010, 101, 2067-2069. [CrossRef] [PubMed]

28. Júnior, O.K.; Gurgel, L.V.A.; de Freitas, R.P.; Gil, L.F. Adsorption of $\mathrm{Cu}(\mathrm{II}), \mathrm{Cd}(\mathrm{II})$, and $\mathrm{Pb}$ (II) from aqueous single metal solutions by mercerized cellulose and mercerized sugarcane bagasse chemically modified with EDTA dianhydride (EDTAD). Carbohydr. Polym. 2009, 77, 643-650. [CrossRef]

29. Yu, J.; Wang, L.; Chi, R.; Zhang, Y.; Xu, Z.; Guo, J. Adsorption of $\mathrm{Pb}^{2+}, \mathrm{Cd}^{2+}, \mathrm{Cu}^{2+}$, and $\mathrm{Zn}^{2+}$ from aqueous solution by modified sugarcane bagasse. Res. Chem. Intermed. 2015, 41, 1525-1541. [CrossRef]

30. Zhu, H.-X.; Cao, X.-J.; He, Y.-C.; Kong, Q.-P.; He, H.; Wang, J. Removal of $\mathrm{Cu}^{2+}$ from aqueous solutions by the novel modified bagasse pulp cellulose: Kinetics, isotherm and mechanism. Carbohydr. Polym. 2015, 129, 115-126. [CrossRef] [PubMed]

31. Ramos, S.N.d.C.; Xavier, A.L.P.; Teodoro, F.S.; Gil, L.F.; Gurgel, L.V.A. Removal of cobalt(II), copper(II), and nickel(II) ions from aqueous solutions using phthalate-functionalized sugarcane bagasse: Mono- and multicomponent adsorption in batch mode. Ind. Crops Prod. 2016, 79, 116-130. [CrossRef]

32. Zheng, Y.; Li, S.; Weng, Z.; Gao, C. Hyperbranched polymers: Advances from synthesis to applications. Chem. Soc. Rev. 2015, 44, 4091-4130. [CrossRef] [PubMed]

33. Camarada, M.B.; Zúñiga, M.; Alzate-Morales, J.; Santos, L.S. Computational study of the complexation of metals ions with poly(amidoamine) PAMAM G0 dendrimers. Chem. Phys. Lett. 2014, 616-617, 171-177. [CrossRef]

34. Zarghami, Z.; Akbari, A.; Latifi, A.M.; Amani, M.A. Design of a new integrated chitosan-PAMAM dendrimer biosorbent for heavy metals removing and study of its adsorption kinetics and thermodynamics. Bioresour. Technol. 2016, 205, 230-238. [CrossRef] [PubMed] 
35. Zang, C.; Zhang, D.; Xiong, J.; Lin, H.; Chen, Y. Preparation of a novel adsorbent and heavy metal ion adsorption. J. Eng. Fibers Fabr. 2014, 9, 165-170.

36. Lin, H.; Han, S.; Dong, Y.; Ling, W.; He, Y. Structural characteristics and functional properties of corncob modified by hyperbranched polyamide for the adsorption of Cr (VI). Water Air Soil Pollut. 2018, 229. [CrossRef]

37. Li, Q.; Xu, B.; Zhuang, L.; Xu, X.; Wang, G.; Zhang, X.; Chen, J.; Yang, T. Preparation, characterization, adsorption kinetics and thermodynamics of chitosan adsorbent grafted with a hyperbranched polymer designed for $\mathrm{Cr}(\mathrm{VI})$ removal. Cellulose 2018, 25, 3471-3486. [CrossRef]

38. Sarker, T.C.; Azam, S.M.G.G.; El-Gawad, A.M.A.; Gaglione, S.A.; Bonanomi, G. Sugarcane bagasse: A potential low-cost biosorbent for the removal of hazardous materials. Clean Technol. Environ. Policy 2017, 19, 2343-2362. [CrossRef]

39. Huang, R.; Liu, Z.; Sun, B.; Fatehi, P. Preparation of dialdehyde cellulose nanocrystal as an adsorbent for creatinine. Can. J. Chem. Eng. 2016, 94, 1435-1441. [CrossRef]

40. Wang, X.-C.; Zhang, F.-F.; Qiang, T.-T.; Guo, P.-Y. Characterization of amino terminated hyperbranced collagen fiber and adsorption thermodynamics to Cr(VI). J. Donghua Univ. 2015, 3, 470-476.

41. Monser, L.; Adhoum, N. Modified activated carbon for the removal of copper, zinc, chromium and cyanide from wastewater. Sep. Purif. Technol. 2002, 26, 137-146. [CrossRef]

42. Lin, J.; Wang, L. Comparison between linear and non-linear forms of pseudo-first-order and pseudo-second-order adsorption kinetic models for the removal of methylene blue by activated carbon. Front. Environ. Sci. Eng. China 2009, 3, 320-324. [CrossRef]

43. Wang, L.; Zhang, J.; Zhao, R.; Li, Y.; Li, C.; Zhang, C. Adsorption of Pb(II) on activated carbon prepared from Polygonum orietale Linn.: Kinetics, isotherms, pH, and ionic strength studies. Bioresour. Technol. 2010, 101, 5808-5814. [CrossRef] [PubMed]

44. Foo, K.Y.; Hameed, B.H. Insights into the modeling of adsorption isotherm systems. Chem. Eng. J. 2010, 156, 2-10. [CrossRef]

(C) 2018 by the authors. Licensee MDPI, Basel, Switzerland. This article is an open access article distributed under the terms and conditions of the Creative Commons Attribution (CC BY) license (http:/ / creativecommons.org/licenses/by/4.0/). 